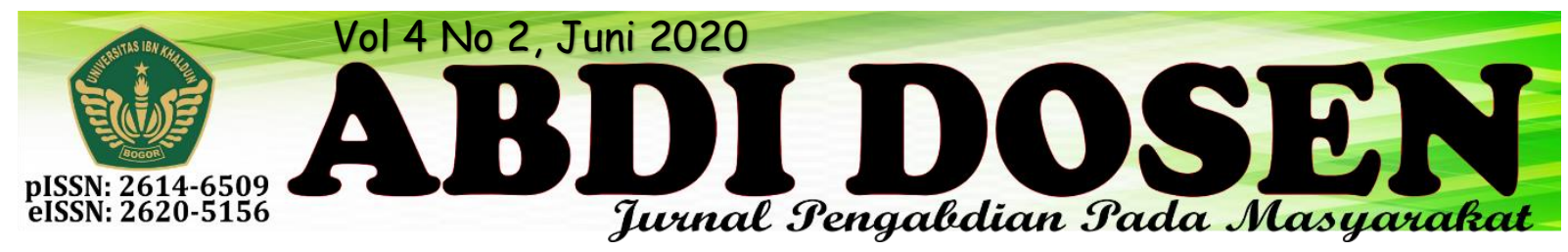

\title{
PENINGKATAN DAN PEMBERDAYAAN MANUSIA CEKATAN (CERDAS, KREATIF, AKHLAKUL KARIMAH, TERAMPIL, SEHAT DAN MANDIRI) MELALUI PENDIDIKAN NONFORMAL DI DESA SIBANTENG
}

\author{
Amalul Umam ${ }^{1}$, Wirda Syari ${ }^{2}$, Alan Nurdiansyah, Amalia Sholeha ${ }^{3}$ \\ amalul.umam@uika-bogor.ac.id ${ }^{1}$ \\ wirda@uika-bogor.ac.id ${ }^{2}$ \\ alannurdiansyah.1605@gmail.com ${ }^{3}$ \\ Fakultas Keguruan dan Ilmu Pendidikan Universitas Ibn Khaldun ${ }^{1}$, Fakultas Ilmu Kesehatan Universitas Ibn \\ Khaldun $^{2}$, Mahasiswa KKN Kelompok 25\&26 Tahun 2019³
}

\begin{abstract}
ABSTRAK
Kuliah Kerja Nyata (KKN) adalah kegiatan mahasiswa dalam mengabdi kepada masyarakat dengan pendekatan lintas keilmuan dan sektoral pada waktu dan daerah tertentu. Dalam pelaksanaan kegiatan KKN ini dilakukan proses perencanaan sekaligus aksi program pendampingan masyarakat baik pada aspek sosial, ekonomi, kesehatan, pendidikan dan agama maupun teknologi tepat guna secara terpadu. Pelaksanaan kegiatan KKN berlangsung sejak tanggal 7 Agustus sampai 5 September 2019 dan bertempat di Desa Sibanteng, Kecamatan Leuwisadeng, Kabupaten Bogor. Permasalahan yang ditemukan di Desa Sibanteng antara lain keterbatasan air bersih karena sedang memasuki musim kemarau, kurangnya kesadaran masyarakat untuk menerapkan perilaku hidup bersih dan sehat (PHBS), serta perlunya peningkatan dalam bidang pendidikan dan pemberdayaan masyarakat. Solusi yang ditawarkan untuk masalah yang ditemukan antara lain membantu warga Desa Sibanteng dalam penyaluran bantuan air bersih, melakukan berbagai kegiatan untuk meningkatkan kesadaran masyarakat untuk menerapkan PHBS (melaksanakan cek kesehatan, nonton bareng film dokumenter lingkungan, penyuluhan cuci tangan, kerja bakti membersihkan lingkungan), serta melakukan berbagai kegiatan untuk peningkatan dalam bidang pendidikan dan pemberdayaan masyarakat (melaksanakan bimbingan belajar, membantu mengajar di sekolah, melakukan renovasi bangunan majelis, pelatihan pembuatan celengan dan dompet koin, serta pembuatan kotak amal untuk masyarakat). Dengan adanya kegiatan KKN ini diharapkan dapat membantu masyarakat dalam mengatasi berbagai permasalahan yang dihadapi.
\end{abstract}

\section{Kata Kunci: Pendidikan Non Formal, Akhlakul Karimah, Manusia Cekatan}

\section{PENDAHULUAN}

Kuliah Kerja Nyata (KKN) adalah kegiatan mahasiswa dalam mengabdi kepada masyarakat dengan pendekatan lintas keilmuan dan sektoral pada waktu dan daerah tertentu. Direktorat Jenderal Pendidikan Tinggi Indonesia mewajibkan setiap perguruan tinggi untuk melaksanakan KKN sebagai kegiatan intrakulikuler yang memadukan tri dharma perguruan tinggi yaitu: pendidikan, penelitian, dan pengabdian kepada masyarakat.

Pelaksanaan kegiatan KKN Tematik 
Terintegrasi Universitas Ibn Khaldun ini berlangsung selama kurang lebih satu bulan dan bertempat di Desa Sibanteng, Kecamatan Leuwisadeng. Dalam pelaksanaan kegiatan ini, mahasiswa melakukan proses perencanaan sekaligus aksi program pendampingan masyarakat baik pada aspek sosial, ekonomi, kesehatan, pendidikan dan agama maupun teknologi tepat guna secara terpadu.

\section{Analisis Situasi}

Desa Sibanteng adalah salah satu desa yang terdekat kepada kantor Desa Sibanteng dimana desa itu memiliki 9 RW, 29 RT, dan 5 Dusun. Desa Sibanteng khususnya Kampung Sibanteng berada pada letak geografis yang cukup rendah yaitu berada pada ketinggian $325 \mathrm{Mdpl}$ sehingga ada banyak persawahan dan perkebunan. Juga terdapat beberapa bangunan sekolah TK, SD, SMP, MAN dan beberapa pondok pesantren. Desa Sibanteng memiliki luas 640.816 Ha dan memiliki batas desa sebagai berikut:

\begin{tabular}{|c|c|c|}
\hline No & Ket & Berbatasan \\
\hline 1 & Utara & $\begin{array}{c}\text { Kecamatan } \\
\text { Cigudeg/Rumpin }\end{array}$ \\
\hline 2 & Selatan & $\begin{array}{l}\text { Desa Leuwisadeng } \\
\text { Desa Sadeng Kolot }\end{array}$ \\
\hline 3 & Barat & Desa Sadeng \\
\hline 4 & Timur & $\begin{array}{l}\text { Desa Leuwisadeng, } \\
\text { Desa Leuwibatu }\end{array}$ \\
\hline
\end{tabular}

\section{Permasalahan yang Ditemukan}

Berdasarkan hasil observasi dan wawancara yang kami lakukan, permasalahan yang ditemukan di Desa Sibanteng khususnya Kampung Sibanteng antara lain:

1. Keterbatasan air bersih karena sedang memasuki musim kemarau.
2. Kurangnya kesadaran masyarakat untuk menerapkan perilaku hidup bersih dan sehat.

3. Perlunya peningkatan dalam bidang pendidikan dan pemberdayaan masyarakat.

\section{Solusi yang Ditawarkan}

Setelah mengetahui dan memahami permasalahan di Desa Sibanteng khususnya Kampung Sibanteng, kami menawarkan beberapa solusi untuk masalah yang dihadapi, yaitu:

1. Membantu warga Desa Sibanteng dalam penyaluran bantuan air bersih.

2. Melakukan berbagai kegiatan untuk meningkatkan kesadaran masyarakat untuk menerapkan perilaku hidup bersih dan sehat, antara lain melakukan cek kesehatan, nonton bareng film dokumenter mengenai lingkungan, penyuluhan cuci tangan, serta kerja bakti membersihkan selokan, tempat sampah dan lingkungan.

3. Melakukan berbagai kegiatan untuk peningkatan dalam bidang pendidikan dan pemberdayaan masyarakat, antara lain melaksanakan bimbingan belajar (Bahasa Inggris, Agama Islam dan Matematika); membantu mengajar di TK, TPA, dan Madrasah; melakukan renovasi bangunan majelis; pelatihan pembuatan celengan dan dompet koin; serta pembuatan kotak amal untuk masyarakat.

Selain kegiatan-kegiatan diatas, dalam pelaksanaan kegiatan KKN ini kami juga turut membantu perangkat desa dalam melaksanakan berbagai kegiatan seperti Peringatan HUT Kemerdekaan RI. 


\section{METODE PELAKSANAAN}

\section{Tahap Pelaksanaan}

Pelaksanaan KKN Tematik Terintegrasi di Desa Sibanteng ini terhitung mulai tanggal 7 Agustus sampai dengan 5 September 2019 dengan tahapan pelaksanaan perminggu. Adapun tahap pelaksanaannya adalah sebagai berikut :

\section{Tahap pelaksanaan $\quad$ Metode $\quad$ Hasil yang diharapkan}

\begin{tabular}{|c|c|c|}
\hline $\begin{array}{l}\text { Bimbingan Belajar } \\
\text { Siang Hari (Bahasa } \\
\text { Inggris, Agama Islam } \\
\text { dan Matematika) }\end{array}$ & $\begin{array}{l}\text { Ceramah } \\
\text { Tanya jawab } \\
\text { Sharing } \\
\text { Praktik percakapan }\end{array}$ & $\begin{array}{l}\text { 1. Pemahaman mata pelajaran } \\
\text { sekolah } \\
\text { 2. Peningkatan kualitas anak } \\
\text { didik } \\
\text { 3. Mampu menghitung dengan } \\
\text { cepat } \\
\text { 4. Fasih berbahasa Inggris } \\
\text { 5. Akhlak terpuji } \\
\text { 6. Menambah pengetahuan }\end{array}$ \\
\hline $\begin{array}{l}\text { Mengajar (TK, TPA dan } \\
\text { Madrasah) }\end{array}$ & $\begin{array}{l}\text { Ceramah } \\
\text { Tanya jawab } \\
\text { Sharing }\end{array}$ & $\begin{array}{l}\text { 1. Mampu meningkatkan } \\
\text { kualitas peserta didik } \\
\text { 2. Menambah pengetahuan } \\
\text { peserta didik } \\
\text { 3. Memberikan pengalaman } \\
\text { kegiatan belajar mengajar }\end{array}$ \\
\hline $\begin{array}{l}\text { Renovasi Bangunan } \\
\text { Majelis RT } 01\end{array}$ & Pengecatan tembok & $\begin{array}{l}\text { Majelis menjadi lebih indah dan } \\
\text { nyaman saat digunakan untuk } \\
\text { pengajian dan kegiatan lainnya }\end{array}$ \\
\hline Cek Kesehatan & $\begin{array}{l}\text { Ceramah } \\
\text { Praktik }\end{array}$ & $\begin{array}{l}\text { Masyarakat bisa menjaga } \\
\text { kesehatannya supaya terhindar } \\
\text { dari penyakit }\end{array}$ \\
\hline $\begin{array}{l}\text { Nonton Bareng Film } \\
\text { Dokumenter }\end{array}$ & Screening film & $\begin{array}{l}\text { Masyarakat bisa lebih menyadari } \\
\text { pentingnya menjaga kebersihan } \\
\text { lingkungan sekitar dan bisa } \\
\text { memahami dampak dari } \\
\text { membuang sampah sembarangan }\end{array}$ \\
\hline $\begin{array}{l}\text { Penyuluhan Cuci } \\
\text { Tangan }\end{array}$ & $\begin{array}{l}\text { Ceramah } \\
\text { Praktik }\end{array}$ & $\begin{array}{l}\text { Anak-anak bisa mengetahui } \\
\text { pentingnya mencuci tangan dan } \\
\text { menjaga kebersihan tangan }\end{array}$ \\
\hline $\begin{array}{l}\text { Pelatihan Pembuatan } \\
\text { Dompet Koin }\end{array}$ & $\begin{array}{l}\text { Ceramah } \\
\text { Praktik }\end{array}$ & $\begin{array}{l}\text { 1. Masyarakat mampu } \\
\text { memanfaatkan barang-barang } \\
\text { bekas } \\
\text { 2. Masyarakat lebih kreatif dan } \\
\text { inovatif }\end{array}$ \\
\hline $\begin{array}{l}\text { Pelatihan Pembuatan } \\
\text { Celengan }\end{array}$ & $\begin{array}{l}\text { Ceramah } \\
\text { Praktik }\end{array}$ & $\begin{array}{l}\text { Anak-anak paham akan } \\
\text { pentingnya menabung untuk } \\
\text { mandiri }\end{array}$ \\
\hline
\end{tabular}




\begin{tabular}{|l|l|l|}
\hline $\begin{array}{l}\text { Memperingati Hari } \\
\text { kemerdekaan RI yang }\end{array}$ & $\begin{array}{l}\text { 1. Berbagai perlombaan } \\
\text { 2. Gerak jalan } \\
\text { 3. Pawai obor }\end{array}$ & $\begin{array}{l}\text { Meningkatakan semangat } \\
\text { nasionalisme masyarakat } \\
\text { Indonesia khususnya masyarakat } \\
\text { Desa Sibanteng }\end{array}$ \\
\hline $\begin{array}{l}\text { Kerja bakti } \\
\text { membersihkan selokan, } \\
\text { tempat sampah dan } \\
\text { lingkungan di RW 03 }\end{array}$ & Kerja bersama-sama & $\begin{array}{l}\text { Menyadarkan masyarakat tentang } \\
\text { pentingnya menjaga lingkungan } \\
\text { agar tetap bersih dan terhindar dari } \\
\text { penyakit }\end{array}$ \\
\hline $\begin{array}{l}\text { Mengikuti berbagai } \\
\text { pengajian di Desa } \\
\text { Sibanteng }\end{array}$ & $\begin{array}{l}\text { Mendengarkan } \\
\text { Memahami }\end{array}$ & $\begin{array}{l}\text { Menambah ilmu dan pemahaman } \\
\text { tentang islam serta memperkuat } \\
\text { ketaqwaan kepada Tuhan yang } \\
\text { Maha Esa }\end{array}$ \\
\hline $\begin{array}{l}\text { Pengadaan Air Bersih } \\
\text { untuk Masyarakat Desa } \\
\text { Sibanteng }\end{array}$ & $\begin{array}{l}\text { Membantu warga dalam } \\
\text { penyaluran bantuan air } \\
\text { bersih dari PDAM }\end{array}$ & $\begin{array}{l}\text { Terpenuhinya kebutuhan } \\
\text { masyarakat akan air bersih }\end{array}$ \\
\hline $\begin{array}{l}\text { Pembuatan Kotak Amal } \\
\text { Bekerja sama } \\
\text { Praktik }\end{array}$ & $\begin{array}{l}\text { Masyarakat bisa lebih giat lagi } \\
\text { untuk beramal }\end{array}$ \\
\hline Santunan Anak Yatim & $\begin{array}{l}\text { Bermusyawarah dengan } \\
\text { masyarakat serta ketua } \\
\text { RW, RT dan MUI } \\
\text { setempat }\end{array}$ & $\begin{array}{l}\text { Memberikan kebahagiaan dan } \\
\text { memperkuat tali silaturahmi } \\
\text { kepada sesama }\end{array}$ \\
\hline
\end{tabular}

\section{Metode Pendekatan}

Dalam melaksanakan Program KKN ini, kami menggunakan beberapa pendekatan antara lain:

1. Pendekatan sosiologis: pendekatan ini bertujuan untuk mengetahui kondisi kehidupan masyarakat sehari-hari.

2. Pendekatan psikologis: pendekatan ini bertujuan untuk melihat kondisi yang menjadi objek kegiatan.

Adapun metode yang digunakan dalam pendekatan ini yaitu dengan observasi langsung kondisi kampung dan kegiatan masyarakat di Kampung Sibanteng Desa Sibanteng. Kemudian, kami juga menggunakan metode wawancara dengan aparatur kampung dan desa, para sepuh dan tokoh masyarakat, serta masyarakat setempat.

Partisipasi Masyarakat dalam Program Partisipasi masyarakat yang dilakukan dalam kegiatan ini adalah sebagai berikut :
1. Kepala Desa dan staf membantu mencari lokasi titik fokus lokasi KKN.

2. Staf Desa, Ketua RT dan Ketua Pemuda membantu mencari tempat hunian selama KKN.

3. Mengizinkan dan mendukung anakanak untuk mengikuti Les Bimbingan Belajar.

4. Mempersiapkan tempat untuk penyuluhan.

5. Bersama dengan kepala desa, staf desa dan BPD desa menyusun perlombaan dalam rangka memperingati hari kemerdekaan RI.

6. Mengizinkan dan mendukung pemasangan spanduk dan plang majelis.

7. Mempersiapkan alat kebersihan dan kerjabakti

8. Bersama-sama membersihkan lingkungan sekitar dan menata lingkungan agar terlihat indah dan nyaman. 


\section{Langkah Evaluasi}

Evaluasi yang telah dan akan dilakukan terdiri dari:

1. Evaluasi proses, yang terkait dengan perencanaan, pelaksanaan dan monitoring kegiatan. Evaluasi proses dilakukan setiap pekan bersama dengan kelompok.

2. Evaluasi hasil, yang akan dilakukan

\section{REALISASI PROGRAM}

\section{a. Pendidikan}

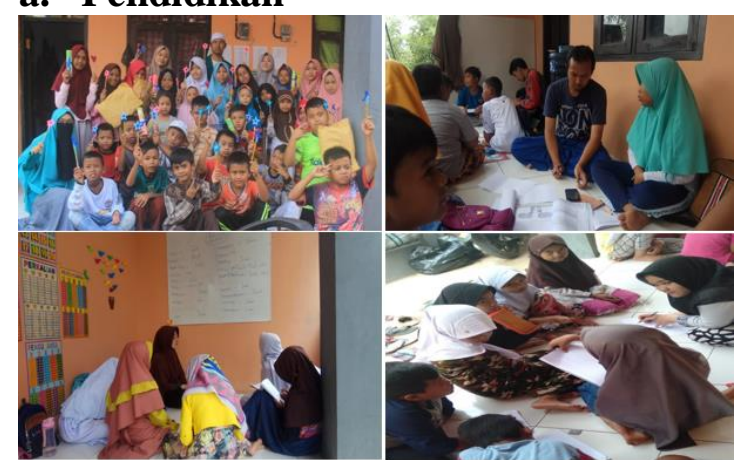

Program Bimbingan Belajar Bahasa

Inggris, Agama Islam, dan Matematika (18 - 29 Agustus 2019)

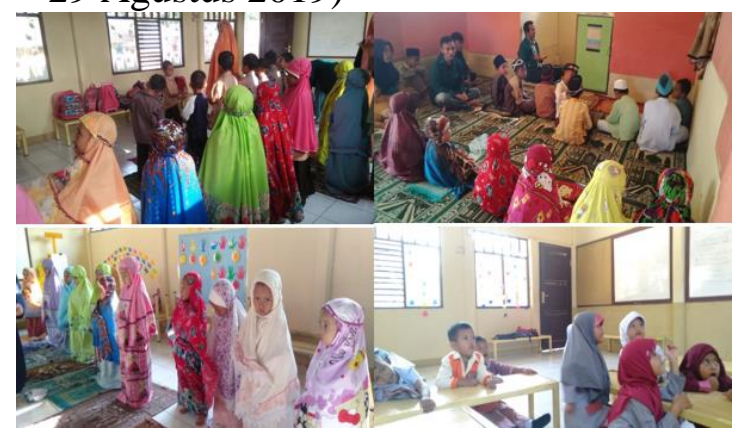

Mengajar TK, TPA, dan Madrasah (14 Agustus - 2 September 2019)

b. Ekonomi

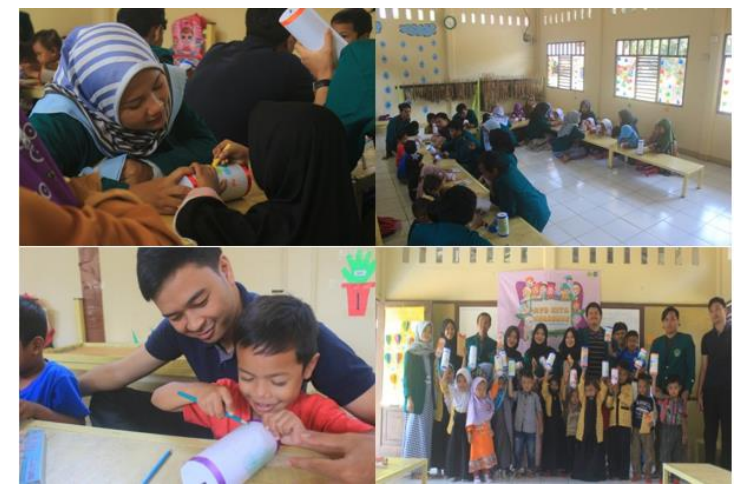

Program Pelatihan Pembuatan Celengan di TPA Granada (20 Agustus 2019) setelah kegiatan dilaksanakan. Evaluasi hasil bertujuan untuk menilai agendaagenda yang telah dilaksanakan selama KKN berlangsung. Evaluasi hasil dilakukan dengan mendatangi desa kembali untuk mengetahui sejauh mana perkembangan yang telah dilakukan selama kurang lebih satu bulan tekahir.

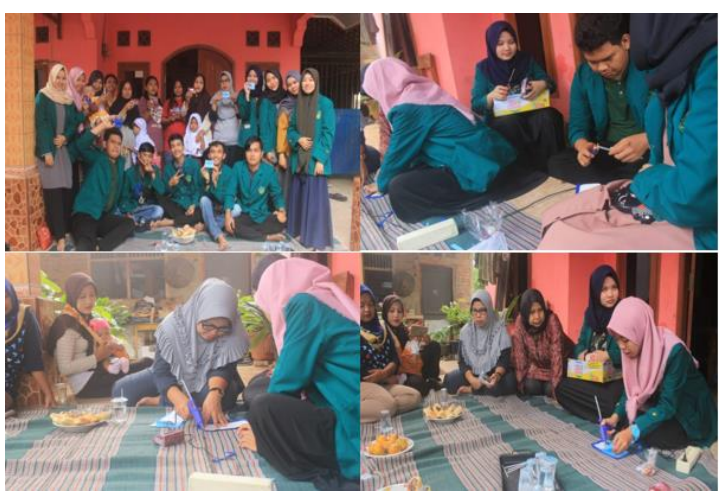

Program Pelatihan Pembuatan Dompet Koin di RT 03 (28 Agustus 2019)

c. Kesehatan

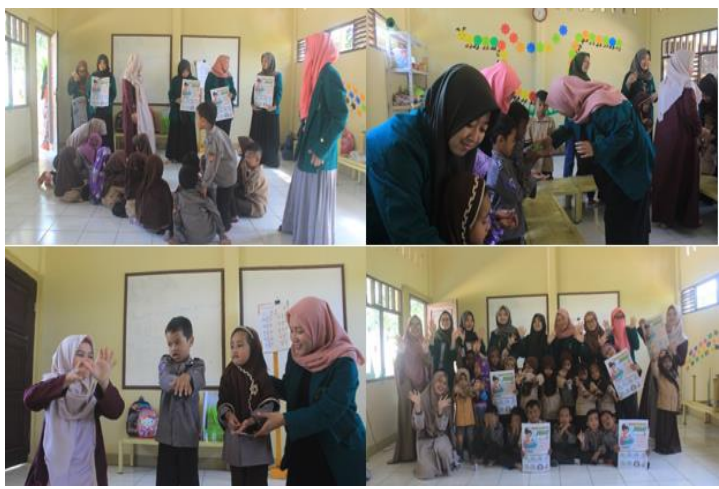

Penyuluhan Cuci Tangan di TPA Granada (21 Agustus 2019)

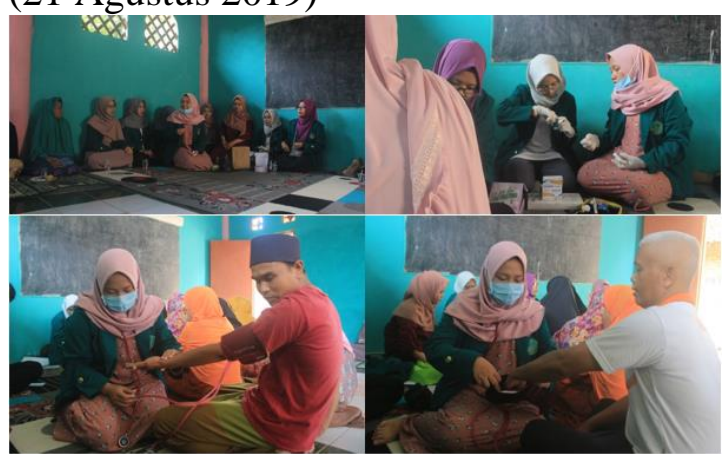

Cek Kesehatan di RT 01 (23 Agustus 2019) 


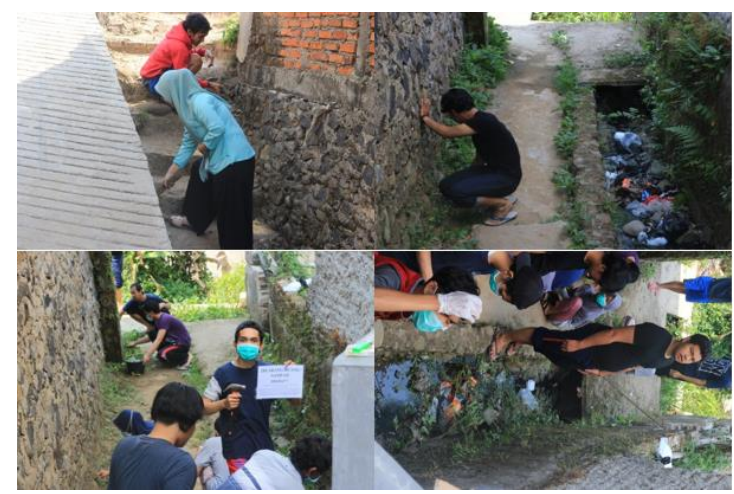

Kerja bakti membersihkan selokan, tempat sampah dan lingkungan di RW 03 (8 - 13 Agustus 2019)

\section{d. Teknik}

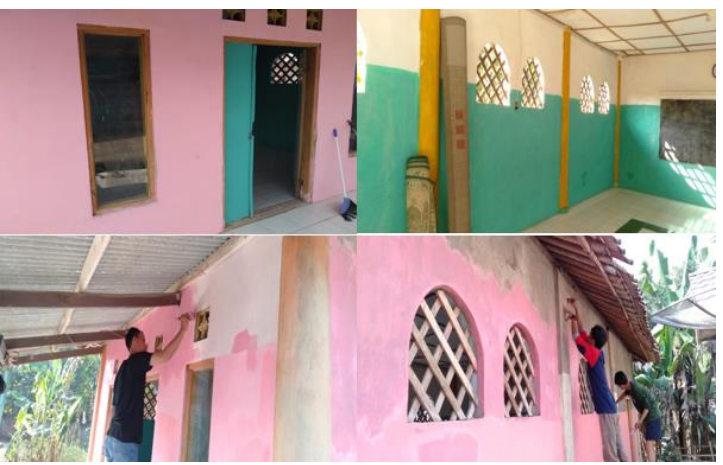

Renovasi Bangunan Majelis (Pengecatan)

(18 Agustus 2019)

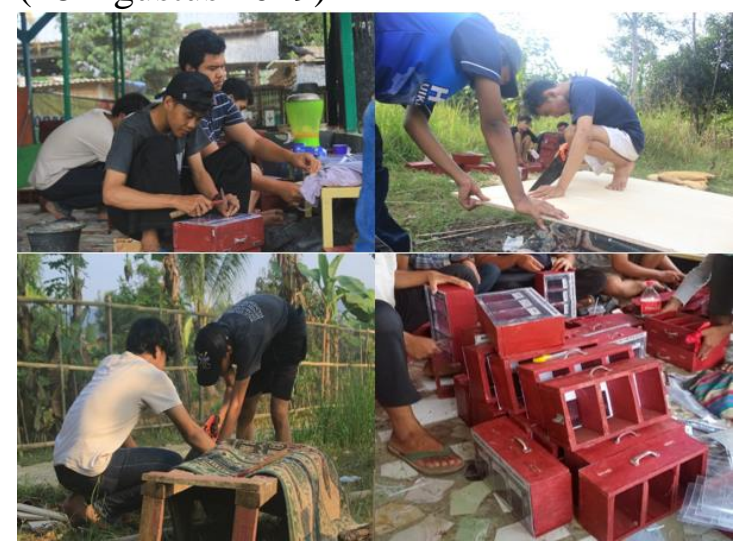

Pembuatan Kotak Amal (21 - 29 Agustus 2019)

\section{e. Agama Islam}

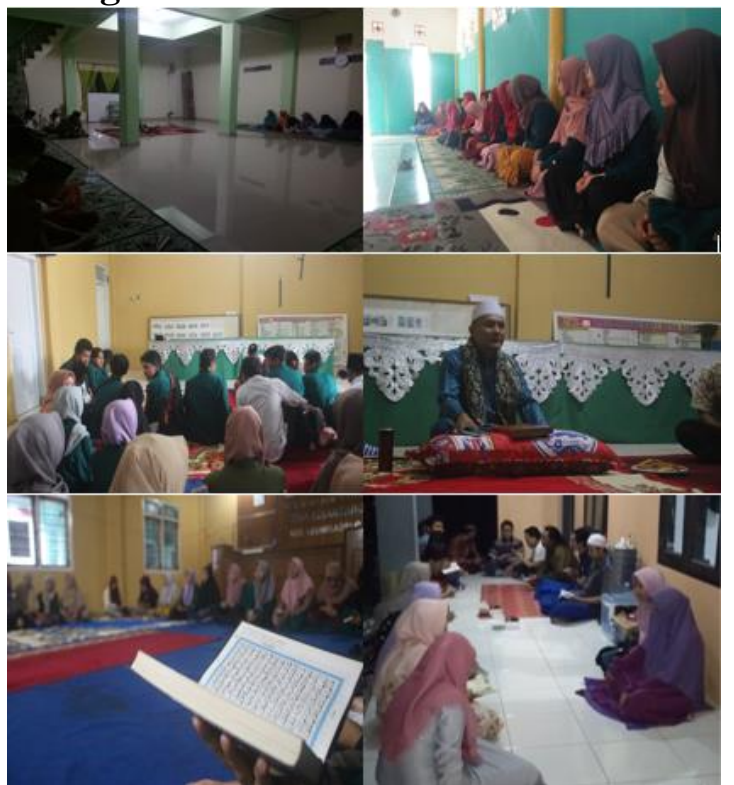

Pengajian Bapak-Bapak, Pengajian

Remaja, Kajian Kitab Ibu-Ibu, Pengajian di Aula Desa, Pengajian Rawatib

\section{f. Program Kerja Kelompok}

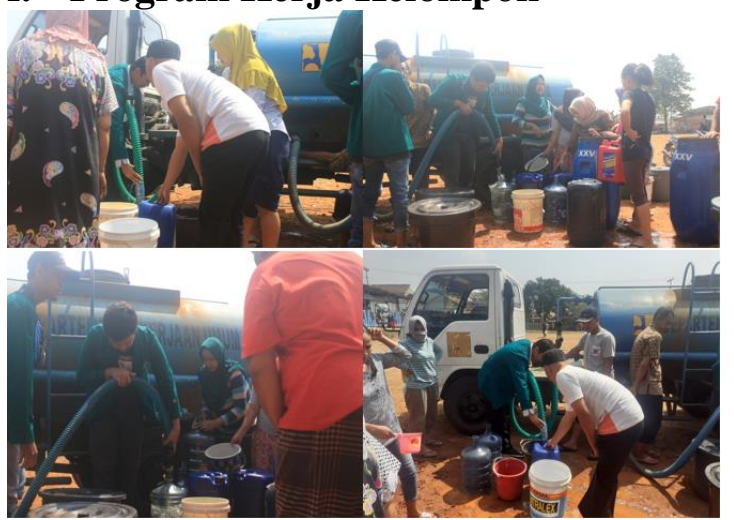

Menyuplai air bersih dari PDAM untuk warga (22 Agustus 2019)

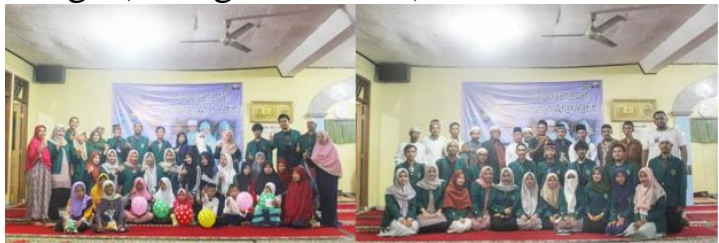

Santunan Anak Yatim (4 September 2019) 


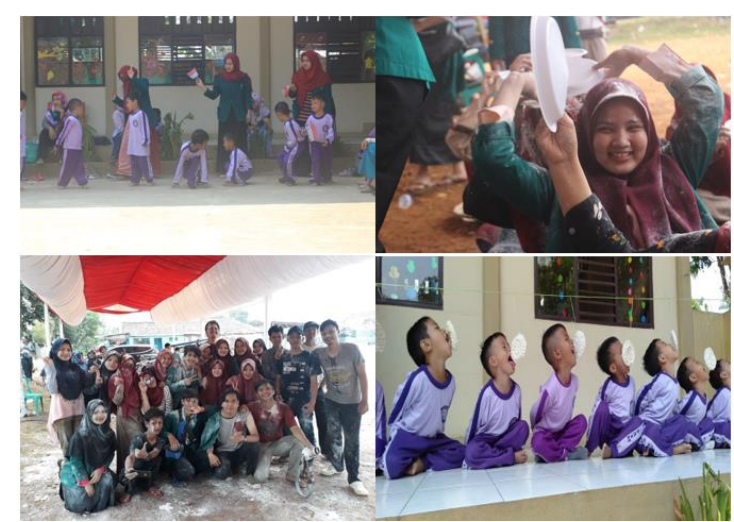

Perlombaan 17 Agustus (17 dan 19

Agustus 2019)

\section{KESIMPULAN}

Secara umum, pelaksanaan kegiatan Kuliah Kerja Nyata (KKN) Tematik Terintegrasi 2019 di Desa Sibanteng Kecamatan Leuwisadeng berjalan lancar sesuai dengan apa yang telah direncanakan meskipun tidak terlepas dari berbagai kekurangan. Keberhasilan pelaksanaan kegiatan KKN ini tidak lepas dari kerjasama yang baik antara mahasiswa, perangkat

\section{DAFTAR PUSTAKA}

Administrasi Profil Desa Sibanteng

Ikhsan, MZ., Prasetya, EP. (2020). Sosialisasi Pendidikan Stop Aksi Bullying. PKM-P, 4 (1).

Joyce, Bruce dan Weil, Marsha. (1996). Models of Teaching Boston: Ailyn and Bacon.

Laporan Bulanan Desa Sibanteng

LPPM UIKA. (2019). Petunjuk Pelaksanaan KKN Tematik Terintegrasi 2019 Universitas Ibn Khaldun. Bogor: UIKA Press.

Rulhendri (2018), Memberdayakan Masyarakat Peduli, Cerdas dan

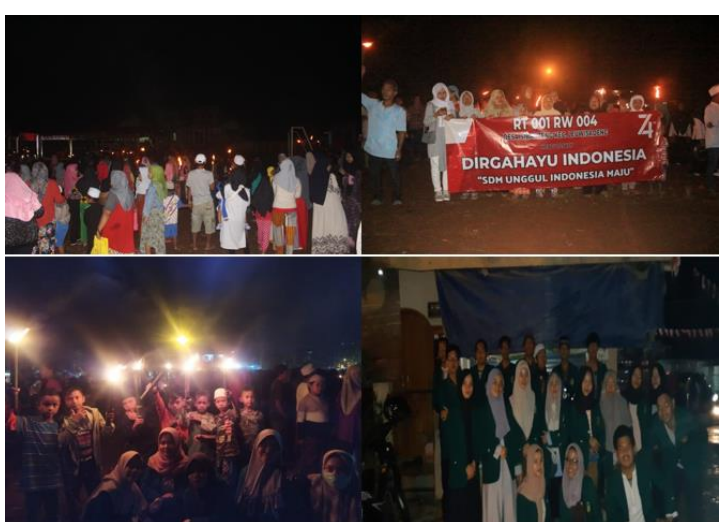

Pawai Obor (16 Agustus 2019)

desa, masyarakat, serta semua pihak yang telah membantu dan mendukung pelaksanaan KKN. Dengan adanya kegiatan KKN ini diharapkan dapat sedikit membantu masyarakat dalam mengatasi berbagai permasalahan yang dihadapi baik dalam bidang sosial, ekonomi, kesehatan, pendidikan dan agama, maupun teknologi.

Bersosial Sehingga Mampu Bersaing Di Era Globalisasi, Jurnal Abdidos

Miradj, S., \& Sumarno, S (2014). Pemberdayaan Masyarakat miskin, melalui proses pendidikan nonformal, upaya meningkatakan kesejahtraan sosial. JPPM (jurnal pendidikan dan pemberdayaan masyarakat), 1(1), 101-112

Web:

htpp://pkm.uika-

bogor.ac.id/index.php/ABDIDOS/iss ue/archive

http:pkm.uika-bogor.ac.id/index.php.pkm$\mathrm{p}$

jurnalnasional.ump.ac.id >index php > JPPM 